\title{
APLICACIÓN DE DIFERENTES NIVELES DE PROTEÍNA Y AMINOÁCIDOS SINTÉTICOS EN EL COMPORTAMIENTO PRODUCTIVO DE CODORNICES
}

\author{
APPLICATION OF DIFFERENT LEVELS OF PROTEIN AND \\ SYNTHETIC AMINO ACIDS IN THE PRODUCTIVE BEHAVIOR \\ OF QUAILS
}

Silvia Patricia Patarón Andino

Nelson Antonio Duchi Duchi

Irma Patarón

Richard Muyulema Erazo

rimuer1@gmail.com 
Para citar este artículo:

Patarón Andino, S. P., Duchi Duchi, N. A., Patarón Andino, I. M., \& Muyulema Erazo, R. N. (2020). Aplicación de diferentes niveles de proteína y aminoácidos sintéticos en el comportamiento productivo de codornices. ESPACIO I+D, INNOVACIÓN MÁS DESARROLLO, 9(24). https://doi.org/10.31644/IMASD.24.2020.a03

\section{RESUMEN}

Se evaluó el efecto de distintos niveles de proteína bruta (Рв) adicionada con aminoácidos sintéticos (AAS) en el comportamiento productivo de codornices de postura. Se utilizaron 500 codornices, las cuales fueron distribuidas aleatoriamente a cuatro tratamientos según un diseño completamente al azar con cinco repeticiones T1: $21 \%$ PB $+0,15 \%$ AAs, T2: $20 \%$ PB $+0,19 \%$ AAS, T3: $19 \%$ Рв $+0,22 \%$ AAS y tratamiento testigo T0: $22 \%$ Рв. Los resultados mostraron que el mejor consumo de los nutrientes se obtuvo en codornices alimentadas con el T2 $(P<0,01)$, para las variables: Materia seca $(22,31 \mathrm{~g} /$ día); Energía metabolizable (0,07 Mcal/Kg); Lisina (0,27 g/día); Metionina (0,08 g/día); Treonina (0,15 g/día). El mayor consumo de Рв fue con el T1 $(P<0,01)$ con $4,61 \mathrm{~g} /$ día. El mejor rendimiento productivo de codornices se obtuvo con el T2 con 83,69\% de producción de huevos. El T2 se ajustó a un modelo lineal de tercer orden $(P<0,01)$ y se encontró que el porcentaje de producción dependerá en $66,90 \%$ de los niveles de proteína con 10,75 g como peso promedio del huevo, 9,00 g la masa total del huevo y $0,80 \%$ de mortalidad. Se observo un ligero incremento en el diámetro transversal para la morfología del huevo el T2 $(P<0,01)$ con $26,10 \mathrm{~mm}$. La mejor relación Beneficio/Costo fue con los animales del T2 y se obtuvo \$1,30 USD. Los aminoácidos sintéticos con bajos niveles de PB mejoran el comportamiento productivo en codornices de postura.

\section{Palabras clave}

Producción de codornices, Alimentación de aves. 
The effect of different levels of crude protein (Рв) added with synthetic amino acids (AAS) on the productive behavior of laying quail was evaluated. 500 quail were used, which were randomly distributed to four treatments according to a completely randomized design with five repetitions T1: $21 \%$ $\mathrm{PB}+0.15 \%$ AAS, T2: $20 \%$ PB $+0.19 \%$ AAS, T3: 19\% PB + 0.22\% AAS and control treatment To: $22 \%$ Рв. The results showed that the best consumption of nutrients was obtained in quail fed with T2 $(P<0.01)$, for the variables: Dry matter (22.31 g / day); Metabolizable energy (0.07 Mcal / Kg); Lysine (0.27 g / day); Methionine (0.08 g / day); Threonine (0.15 g / day). The highest consumption of Рв was with T1 $(P<0.01)$ with $4.61 \mathrm{~g} /$ day. The best productive performance of quail was obtained with T2 with $83.69 \%$ of egg production. The T2 was adjusted to a third order linear model $(P<0.01)$ and it was found that the production percentage will depend on $66.90 \%$ of the protein levels with $10.75 \mathrm{~g}$ as the average egg weight, 9, oo g total egg mass and $0.80 \%$ mortality. A slight increase in the transverse diameter was observed for the morphology of the T2 egg $(P<0.01)$ with $26.10 \mathrm{~mm}$. The best Benefit / Cost ratio was with animals in T2 and \$ 1.30 was obtained. Synthetic amino acids with low PB levels improve the productive behavior in laying quail.

\section{Keywords}

Quail production, Bird feeding. 
L a avicultura surgió como una actividad complementaria de los sistemas agrícolas, en las cuales las aves se alimentaban con semillas excedentes de las cosechas y alimentos naturales tomados de su entorno (gusanos, lombrices, etc.) (Pitakpongjaroen \& Wiboonpongse, 2015), mientras que, las enfermedades se trataban con base en los conocimientos tradicionales (Syakalima, Simuunza \& Zulu, 2017). A su vez, las aves reducían algunas plagas de la granja, abonaban los terrenos con estiércol y contribuían con carne y huevos a la alimentación familiar (Tovar, Narváez \& Agudelo, 2015).

En Ecuador, la industria avícola comenzó durante 1950 y 1960 y en los últimos años se introdujo mejoras en la genética de las razas para engorde y en la alimentación (Orellana, 2014). Las líneas genéticas utilizadas por las empresas ecuatorianas en la producción de pollos son Cobb y Ross (Ruiz, 2016). La codorniz es la especie de menor contextura que se explota en el sector avícola comercial (Panda \& Singh, 1990). La razón de su éxito se explica por el alto nivel de producción y por la calidad nutricional del huevo, lo cual ha permitido su aceptación en el mercado (Iqbal et al., 2015).

La crianza de codorniz (Coturnix coturnix japonica) es una actividad avícola de alto rendimiento. La baja inversión inicial, los pocos requerimientos de espacios de terreno, el rápido retorno de capital, el valor nutricional de carne y huevo, el bajo costo de producción, el alto nivel productivo; el rápido crecimiento, la rusticidad y la precocidad de esta especie, son algunas características que hacen atractiva la producción y la convierte en una fuente alternativa de nutrientes con la producción de huevo (Ciriaco \& Roncal, 2016).

La codorniz japónica ha generado gran interés en los avicultores dedicados a la producción de huevo en Ecuador, dado que requiere poca inversión económica para su crianza (Özsoy \& Aktan, 2011). Por lo anterior, el objetivo del presente estudio es evaluar la cantidad de proteína bruta más aminoácidos sintéticos y su respuesta en el comportamiento productivo de la codorniz de postura.

\section{MATERIALES Y MÉTODOS}

\section{Localización del área de estudio}

La presente investigación se desarrolló en la granja de codornices "Reina del Quinche” ubicada en la parroquia Veloz, cantón Riobamba, provincia de Chimborazo, Ecuador, la cual duró 120 días. El análisis bromatológico de las dietas utilizadas se realizó en el laboratorio del Instituto Nacional de Investigaciones Agropecuarias (INIAP). 


\section{Unidades Experimentales}

El número de unidades experimentales fue de 500 codornices, las cuales se distribuyeron al azar en cuatro tratamientos y cinco repeticiones por tratamiento, con un tamaño de unidad experimental de 25 aves.

\section{Tratamiento y diseño experimental}

Los tratamientos experimentales fueron los niveles de proteína bruta (Рв) más la cantidad de aminoácidos sintéticos (AAS): T1: 21\% PB + 0,15\% AA; T2: $20 \%$ РB + 0,19\% AAS; T3: 19\% РВ + 0,22\% AAS у T4: $22 \%$ Рв (tratamiento testigo). Se utilizó un diseño completamente al azar, con el siguiente modelo lineal aditivo:

$$
\mathrm{y}_{\mathrm{ij}}=\mu+\tau_{\mathrm{i}}+\mathcal{E}_{\mathrm{ij}}
$$

Dónde:

$\mathrm{y}_{\mathrm{ij}}=$ Observación en j-esima repetición i-esimo nivel de proteína bruta

$\mu=$ Media general

$\tau_{\mathrm{i}}=$ Efecto del i-esimo nivel de proteína bruta $(19,20,21,22 \%)$

$\varepsilon_{\mathrm{ij}}=$ Error Experimental

\section{Análisis estadístico y pruebas de significancia}

Los resultados numéricos de campo y de laboratorio determinados en la presente investigación, fueron procesados usando el programa estadístico SPSS (versión 18) y Excel 2013 (Microsoft Office ${ }^{\circledR}$ ), realizando los siguientes análisis estadísticos: Análisis de varianza, análisis de correlación y regresión y separación de medias usando la prueba de Waller Duncan con nivel de significancia de $\mathrm{P}<0,05$ y $\mathrm{P}<0,01$.

\section{Procedimiento Experimental}

El área de estudio se desinfectó con AQUAT 50 (Compuesto de Amonio Cuaternario al 20\%) a razón de $1 \mathrm{~mL}$ por litro de agua, el cual se aplicó por aspersión con bomba de mochila, siete días antes de la recepción de las codornices. Se aplicó yodo para la asepsia de comederos y bebederos en dosis de $2 \mathrm{~mL}$ por litro de agua, cuatro días antes de la llegada de las aves. 
A todas las codornices se les administró agua con electrolitos más vitaminas para reducir el estrés por traslado. A la segunda semana de recepción de las aves, se evaluó el consumo de alimento y la producción se estimó en porcentaje. Se consideraron los primeros siete días como período crítico para ofrecer la dieta de adaptación.

Todas las aves se pesaron diariamente y se colocaron en los comederos lineales. A todas ellas, se les ofreció $25 \mathrm{~g}$ de alimento ave/día y agua ad libitum mediante bebederos automáticos tipo copa, a los cuales se les adicionó vitaminas para reducir estrés durante el despique. Esta práctica de manejo se realizó a los 15 días de permanencia y se utilizó cautín eléctrico, yodo y vitaminas. Cada dos meses se les aplicó en el ojo la vacuna mixta contra Newcastle y Bronquitis infecciosa, para bajar la carga bacteriana se realizaron nebulizaciones con yodo dos veces a la semana, y para evitar el ataque de hongos, se les suministró $1 \mathrm{~mL}$ de yodo por litro de agua una sola vez al día.

La producción de huevos se cuantificó diariamente y se realizó dos veces al día (8:00 am y 5:30 pm) con una canastilla de plástico. Para ello, se les ofreció 14 horas de luz natural o artificial, la energía eléctrica se activó de las 6:00 a las 10:00 pm.

Se utilizó un termómetro para controlar la temperatura entre 18 a 22 ${ }^{\circ} \mathrm{C}$ y para evitar corrientes de aire se procuró el manejo de las cortinas para crear un microambiente. La limpieza de la codornaza se realizó con pala y escoba cada 15 días para disminuir la acumulación de amoniaco y no afectar las vías respiratorias de las aves, se esparció en el piso una capa de cal y de cascarilla de arroz (Salinas, 2015).

\section{RESULTADOS Y DISCUSIÓN}

\section{Consumo de nutrientes}

\section{Consumo total de alimento}

El consumo total de alimento en codornices de postura con diferentes niveles de proteína más aminoácidos sintéticos fue diferente $(\mathrm{P}<0,01)$, El menor consumo se obtuvo con T1 (Tabla 1 ). El consumo diario de alimento fue diferente $(P<0,01)$. El mayor consumo diario de alimento se registró en las codornices tratadas con T2, To y T3; y el menor consumo con T1 (Tabla 1). 


\section{Tabla 1}

Consumo de nutrientes en codornices de postura tratadas con aminoácidos sintéticos con bajos niveles de proteína bruta en la dieta

\begin{tabular}{|c|c|c|c|c|c|c|}
\hline \multirow{2}{*}{ VARIABLES } & \multicolumn{5}{|c|}{ TRATAMIENTOS } & \multirow[b]{2}{*}{ Prob. } \\
\hline & TO & $\mathrm{T} 1$ & $\mathrm{T2}$ & T3 & $\mathrm{EE}$ & \\
\hline Consumo total de alimento, $\mathrm{kg}$ & $2,34 \mathrm{a}$ & $2,25 b$ & $2,34 \mathrm{a}$ & $2,33 \mathrm{a}$ & 0,0063 & 0,001 \\
\hline Consumo de alimento, MS g/día & $22,29 \mathrm{a}$ & $21,43 b$ & $22,31 \mathrm{a}$ & $22,20 \mathrm{a}$ & 0,0629 & 0,001 \\
\hline Consumo de proteína bruta, g/día & $4,03 d$ & $4,61 \mathrm{a}$ & $4,48 b$ & $4,38 c$ & 0,0141 & 0,001 \\
\hline Consumo de EM, Mcal/día & $0,07 \mathrm{a}$ & $0,06 \mathrm{~b}$ & $0,07 \mathrm{a}$ & $0,07 \mathrm{a}$ & 0,0007 & 0,002 \\
\hline Consumo de calcio, g/día & $0,81 \mathrm{a}$ & $0,80 a b$ & $0,78 b$ & $0,71 \mathrm{c}$ & 0,0024 & 0,001 \\
\hline Consumo de fósforo, g/día & $0,12 b$ & $0,11 \mathrm{c}$ & $0,11 \mathrm{c}$ & $0,13 \mathrm{a}$ & 0,0006 & 0,001 \\
\hline Consumo de lisina, g/día & $0,20 c$ & $0,23 b$ & $0,27 \mathrm{a}$ & $0,23 b$ & 0,0007 & 0,001 \\
\hline Consumo de metionina, g/día & $0,06 \mathrm{c}$ & $0,06 \mathrm{c}$ & $0,08 \mathrm{a}$ & $0,07 \mathrm{~b}$ & 0,0008 & 0,001 \\
\hline Consumo de treonina, g/día & $0,11 \mathrm{c}$ & $0,13 b$ & $0,15 \mathrm{a}$ & $0,13 b$ & 0,0004 & 0,001 \\
\hline \multicolumn{7}{|c|}{$\begin{array}{l}\text { Letras iguales no difieren significativamente según Waller Duncan }(P<0,05 \text { y } P<0,01) \text {. } \\
\text { EE: Error estándar. } \\
\text { Prob: Probabilidad. } \\
\text { EM: Energía metabolizable. }\end{array}$} \\
\hline
\end{tabular}

Fuente: Elaboración propia

Respecto a estos resultados Tapia (2010) registró un consumo de 22,33 g/ ave/día, y el consumo total de 2,74 Kg. Hurtado, Torres \& Ocampo (2013) concluyeron que la proteína interfiere directamente con el consumo del pienso por ave, mediante el aumento o disminución de su porcentaje dentro de la ración, de acuerdo con el total de kcal ofrecidas.

\section{Consumo de proteína bruta}

El consumo de proteína en codornices de postura tratadas con aminoácidos sintéticos en la presente investigación mostró diferencias estadísticas entre tratamientos $(P<0,01)$. El mayor consumo se registró con el T1 y el menor consumo con el tratamiento testigo (Tabla 1). Estos resultados son menores al promedio obtenido por Yamane, Ono \& Tanaka (2007) y Portillo (2005) con promedios de 4,9 g/día y 5,47 g/día en su respectivo orden variando de acuerdo al consumo de alimento y el porcentaje de proteína en la dieta. De manera similar, Begin \& Insko (1994) determinaron que se requiere 4,71 g/ día cuando la tasa de postura es de $78 \%$ a $80 \%$ con una dieta de $21 \%$ a 22,9 \% de proteína y $2600 \mathrm{Kcal} / \mathrm{kg}$ de EM. 


\section{Consumo de energía}

Las aves del T1 presentaron el promedio más bajo de consumo de EM, lo cual difiere $(P<0,01)$ del resto de los tratamientos (Tabla 1). Estos valores coinciden con los reportados por Yamane, Ono \& Tanaka (2007) quienes obtuvieron parámetros normales con un consumo de 0,062 Mcal/día.

Labier \& Leclercq (1992) encontraron necesidades diarias de 0,082 $\mathrm{Mcal} /$ día para codornices con peso promedio de $220 \mathrm{~g}$ y demostraron que el nivel energético incide en el índice de conversión y la masa huevo.

\section{Consumo de calcio}

Los promedios del consumo de calcio presentaron diferencias $(P<0,01)$. E1 menor consumo se registró con las codornices tratadas con T2 y T3 (Tabla 1). Estos resultados superan a los encontrados por Shrivastav \& Panda (1999) quienes manifestaron que para la puesta son necesarios entre $550 \mathrm{mg} \mathrm{y}$ $650 \mathrm{mg} /$ codorniz/día de consumo de calcio equivalente a 0,55 y 0,65 g/ día según el peso del ave, mismo que puede variar de 140 a 220 g y la masa de huevo puesta diariamente de 9 o 10 g. De manera similar, estos datos superan los resultados presentados por Labier \& Leclercq (1992) con un promedio de $730 \mathrm{mg}$ de consumo de calcio correspondiente a 0,73 g/día.

\section{Consumo de fósforo}

Para el consumo de fósforo se encontraron diferencias $(P<0,01)$. El mayor consumo se presentó en codornices del T3 y el menor consumo con el T1 y el T2 (Tabla 1). El consumo de fósforo obtenidos en la presente investigación son superiores a los registrados por Shrivastav \& Panda (1999) e inferiores a los reportados por Labier \& Leclercq (1992) en donde se alcanzan promedios de 0,055 y 0,15 g/codorniz/día. Shrivastav \& Panda (1999) mencionaron que la proporción de calcio y fosforo en las raciones o piensos avícolas se conoce como relación calcio/fósforo, que para codornices en producción, es de 4:1, la cual difiere con la reportada en la presente investigación, la relación calcio/fósforo fue 6:1 para To; 7:1 para T1 y T2; y 5:1 para $\mathrm{T} 3$.

\section{Consumo de lisina}

El consumo diario de lisina por ave presentó diferencias $(P<0,01)$. El mayor consumo se obtuvo con T2 y el menor consumo con el tratamiento testigo (Tabla 1).

Oliveira et al. (1999) probaron dos niveles de proteína bruta en la ración $(19,0$ y $14,1 \%)$ suplementadas con cinco niveles de lisina $(0,65 ; 0,85 ; 1,05$; 
$1,25$ y $1,45 \%)$, y concluyeron que el mejor peso y la mayor producción de huevos se consiguió con 1,05\% de lisina y 19\% de proteína bruta. Los autores explicaron, que por el bajo contenido proteico de la ración, aumentó el catabolismo y se desviaron los grupos amino de la proteína para la síntesis de aminoácidos no esenciales o ácido úrico.

\section{Consumo de metionina}

El consumo de metionina de las codornices evaluadas fue diferente $(P<0,01)$. El mayor consumo de metionina se registró con T2 y el menor consumo con el tratamiento testigo y el T1 (Tabla 1). El mayor consumo obtenido en la presente investigación es igual al consumo de metionina logrado por Yamane, Ono \& Tanaka (2007) quienes indicaron que la producción óptima sin perjudicar el índice de consumo se consigue con una ingesta diaria de o,08 g/ave/día.

\section{Consumo de treonina}

El consumo de treonina presentó diferencias $(P<0,01)$. El mayor consumo se obtuvo con T2 y el menor consumo con el tratamiento testigo (Tabla 1). Los resultados anteriores superan a los encontrados por Yamane, Ono \& Tanaka (2007) mismos que indican que la producción no se afecta con una ingesta diaria de $110 \mathrm{mg}$ de treonina equivalentes a $0,11 \mathrm{~g} /$ día/codorniz con dietas del $22 \%$ de proteína.

El efecto tóxico de la treonina en el alimento se considera poco o nulo, ya que el organismo la metaboliza con facilidad, al igual que a sus compuestos derivados. Por lo tanto, no se considera un aminoácido de la toxicidad la histidina, triptófano y metionina (Castañón, 1994).

\section{Comportamiento productivo}

\section{Peso al inicio de postura}

En el análisis de varianza del peso de las codornices al inicio de la postura, el mejor tratamiento fue el tratamiento control con 181,44 g, mientras que el T1 fue menor con 174,92 g, para el T2 se obtuvo un valor de 173,21 g, y el último fue el T3 con 168,68 g (Tabla 2). Resultados que, al ser comparados con Ortega (2011) en su estudio acerca de la determinación del efecto en diferentes temperaturas microambientales en la fase inicial, crecimiento, desarrollo y postura en codornices, reportó un peso al inicio de postura de 170,74 g, resultados inferiores a los encontrados en la presente investigación. 


\section{Peso final}

El análisis de varianza del peso final no registró diferencias estadísticas ( $P>$ 0,05), así los promedios fueron de 196,84; 195,44; 195,24 y 192,23 $\pm 1,4978 \mathrm{~g}$ correspondiente a T1, To, T3 y T2 respectivamente ver Tabla 2.

De acuerdo a los resultados obtenidos durante el periodo investigativo, al ser confrontados con los valores hallados por Ortega (2011) y Obregón (2012), muestran inferioridad ya que estos registraron pesos de 208,84 y 201,04 g.

\section{Porcentaje de codornices en producción}

El porcentaje de producción presentó diferencias estadísticas $(P<0,01)$, en donde el porcentaje de producción en codornices tratadas con T2 presentó el mayor promedio con 83,69\% seguido por codornices alimentadas con T3 y To con $79,13 \%$ y $78,51 \%$ de producción en su respectivo orden y con un menor porcentaje de producción de huevos se registró en codornices tratadas con T1 con $75,27 \%$ con una dispersión para cada media de $\pm 0,4724 \%$ (Tabla 2 ).

Hurtado et al. (2013) en su estudio acerca del efecto de niveles de proteína sobre el desempeño de codornices japonesas en fase de postura obtienen el mayor porcentaje en codornices alimentadas con 20,5 \% Рв у $2850 \mathrm{Kcal} / \mathrm{Kg}$ con un promedio de $84,69 \%$ en tanto que el menor porcentaje lo obtuvieron con dietas cuya proteína fue de $22 \%$ y $3050 \mathrm{Kcal} / \mathrm{Kg}$ con un promedio de $79,23 \%$ resultados que son corroborados por la presente investigación.

\section{Masa total de huevos}

Se registraron diferencias significativas $(P<0,01)$ para esta variable, encontrándose la respuesta más elevada en las aves del T2 con una media de 9,oog, seguidos por el tratamiento testigo con $8,46 \mathrm{~g}$, finalmente el tratamiento $\mathrm{T} 3$ y T1 que compartieron significancia con promedios de 8,$38 ; 8,07$ g y con una dispersión para cada media de $\pm 0,0555 \mathrm{~g}$ (Tabla 2).

Los resultados obtenidos en esta investigación supera a los hallados por Moura et al. (2009) y que a la vez es menor al encontrado por Ortega (2011) con medias de 8,09 y 10,72 g.

\section{Porcentaje de mortalidad}

El análisis de varianza para el porcentaje de mortalidad en la fase de producción no reporto diferencias estadísticas entre las medias de los tratamientos $(P>0,05)$ sin embargo numéricamente el menor porcentaje de 
mortalidad fue para T2 con $0,80 \%$ seguido por 1,60\% para T1 y compartiendo el mismo rango To y T3 con $2,40 \%$ teniendo una dispersión para cada media de $\pm 0,5797 \%$ como se señala en la Tabla 2 .

\section{Tabla 2}

Comportamiento productivo de codornices postura tratadas con aminoácidos sintéticos con bajos niveles de proteína bruta en la dieta

\begin{tabular}{|c|c|c|c|c|c|c|}
\hline \multirow{2}{*}{$\begin{array}{l}\text { VARIABLES } \\
\text { PRODUCTIVAS }\end{array}$} & \multicolumn{5}{|c|}{ TRATAMIENTOS } & \multirow[b]{2}{*}{ Prob. } \\
\hline & TO & $\mathrm{T} 1$ & $\mathrm{~T} 2$ & T3 & $\mathrm{EE}$ & \\
\hline Peso a inicio de postura, $g$ & $181,44 \mathrm{a}$ & 174,92 a & $173,21 \mathrm{a}$ & $16,68 \mathrm{a}$ & 1,3464 & 0,057 \\
\hline Peso final, $g$ & $195,44 \mathrm{a}$ & $196,84 \mathrm{a}$ & $195,23 \mathrm{a}$ & $192,24 \mathrm{a}$ & 1,4978 & 0,801 \\
\hline Aves en producción, \% & $78,51 \mathrm{~b}$ & $75,27 c$ & 83,69 a & $79,13 b$ & 0,4724 & 0,001 \\
\hline Masa total de huevos, $g$ & $8,46 b$ & $8,07 \mathrm{c}$ & $9,00 \mathrm{a}$ & $8,38 \mathrm{bc}$ & 0,0555 & 0,001 \\
\hline Porcentaje de mortalidad, \% & $2,40 \mathrm{a}$ & $1,60 \mathrm{a}$ & $0,80 \mathrm{a}$ & $2,40 \mathrm{a}$ & 0,5797 & 0,790 \\
\hline \multicolumn{7}{|c|}{$\begin{array}{l}\text { Letras iguales no difieren significativamente según Waller Duncan }(P<0,05 \text { y } P<0,01) \text {. } \\
\text { EE: Error estándar. } \\
\text { Prob: Probabilidad. }\end{array}$} \\
\hline
\end{tabular}

Fuente: Elaboración propia

Sin embargo, Amarrilla \& Albornoz (2013), reportaron que la mortalidad en la etapa de postura no debe sobrepasar el $4 \%$, en tanto que para el nacimiento y desarrollo debe ser de $10 \%$ y para aves cuyo propósito es el engorde será de $5 \%$.

De manera similar estos resultados son menores a los encontrados por Obregón (2012) quien en su estudio acerca de la utilización de diferentes niveles de promotor de crecimiento natural hibotek en la cría, desarrollo y levante de codornices y su efecto hasta alcanzar el pico de producción, consiguió el 10\% de mortalidad esto se da a la adición de treonina en las dietas puesto que esta tiene importancia en la respuesta inmune humoral ya que es necesaria para la formación de las regiones hipervariables de las inmunoglobulinas o anticuerpos.

Evaluación de la estructura del huevo

\section{Peso del huevo}

En el peso del huevo no se reportaron diferencias significativas $(P>0,05)$, siendo 10,78, 10,75, 10,72 y 10,60 \pm 0,04374 g para los tratamientos To, T2, T1 y $\mathrm{T} 3$ respectivamente. (Tabla 3 ). 


\section{Tabla 3}

Evaluación de los componentes del huevo de codorniz tratados con aminoácidos sintéticos con bajos niveles de proteína bruta en la dieta

\begin{tabular}{|c|c|c|c|c|c|c|}
\hline \multirow{2}{*}{ ESTRUCTURA DEL HUEVO } & \multicolumn{4}{|c|}{ TRATAMIENTOS } & \multirow[b]{2}{*}{$\mathrm{EE}$} & \multirow[b]{2}{*}{ Prob. } \\
\hline & TO & $\mathrm{T} 1$ & $\mathrm{~T} 2$ & T3 & & \\
\hline Peso del huevo, $g$ & $10,78 \mathrm{a}$ & $10,72 \mathrm{a}$ & $10,75 \mathrm{a}$ & $10,60 \mathrm{a}$ & 0,0434 & 0,571 \\
\hline Peso de la cáscara, $g$ & $1,51 \mathrm{a}$ & $1,48 \mathrm{a}$ & $1,43 \mathrm{a}$ & $1,47 \mathrm{a}$ & 0,0110 & 0,168 \\
\hline Peso de la yema, $g$ & $3,58 \mathrm{a}$ & $3,54 \mathrm{a}$ & $3,62 \mathrm{a}$ & $3,53 \mathrm{a}$ & 0,0268 & 0,714 \\
\hline Peso del albumen, $g$ & $5,69 \mathrm{a}$ & $5,70 \mathrm{a}$ & $5,71 \mathrm{a}$ & $5,60 \mathrm{a}$ & 0,0316 & 0,676 \\
\hline Diámetro longitudinal, mm & $31,64 \mathrm{a}$ & $31,78 \mathrm{a}$ & $31,79 \mathrm{a}$ & $31,62 \mathrm{a}$ & 0,0892 & 0,899 \\
\hline Diámetro transversal, mm & $25,22 b$ & $25,29 b$ & $26,10 \mathrm{a}$ & $25,02 b$ & 0,0460 & 0,001 \\
\hline Grosor de la cáscara, mm & $0,20 \mathrm{a}$ & $0,20 \mathrm{a}$ & $0,19 \mathrm{a}$ & $0,20 \mathrm{a}$ & 0,0013 & 0,541 \\
\hline \multicolumn{7}{|c|}{$\begin{array}{l}\text { Letras iguales no difieren significativamente según Waller Duncan }(P<0,05 \text { y } P<0,01) \text {. } \\
\text { EE: Error estándar. } \\
\text { Prob: Probabilidad. }\end{array}$} \\
\hline
\end{tabular}

Fuente: Elaboración propia

Pero en la investigación de Moura et al. (2000), alcanzó un peso medio de 10,33 g inferior a los alcanzados en la presente investigación, señalando que los niveles de lisina no son suficientes para promover el máximo peso de los huevos, sugiriendo que la exigencia de lisina para peso de los huevos es más elevada que el nivel para su producción.

\section{Peso de la cáscara}

Para esta variable no se encontró diferencias estadísticas al utilizar la prueba de Tukey ( $\mathrm{P}>0,05$ ) siendo los promedios de 1,$51 ; 1,48 ; 1,43$ y $1,47 \mathrm{~g}$ para los tratamientos To, T1, T2 y T3 en su respectivo orden con una dispersión para cada media de $\pm 0,0110$ g. (Tabla 3 ). Los resultados hallados son superiores a los encontrados por Melo et al. (2008) quienes utilizaron una ración suplementada con $0,50 \%$ de harina de algas marinas reportando un peso en la cáscara de $1,13 \mathrm{~g}$.

\section{Peso de la yema}

Para el peso de la yema no se encontraron diferencias significativas ( $\mathrm{P}>0,05)$, siendo los promedios para T2, To, T1, T3 de 3,62; 3,58; 3,54 y $3,53 \mathrm{~g}$ en su respectivo orden y con una dispersión para cada media de \pm 0,0268 g. (Tabla 3).

Estos resultados son superiores a los encontrados por Melo et al. (2008) en su investigación donde mencionan la calidad del huevo de codornices 
al utilizar harina de algas marinas y fosfato monoamónico, utilizado como fuente alternativa de fósforo con una media de 3,20 g, de manera similar Moura et al. (2009) reportaron un promedio de 3,19 g en su estudio donde habla sobre el efecto de diferentes niveles dietéticos de lisina total sobre la calidad del huevo de codornices japonesas.

\section{Peso del albumen}

El añadir aminoácidos sintéticos en dietas con bajos niveles de proteína no mostró diferencias significativas $(P>0,05)$, hallándose pesos de 5,71; 5,70; 5,69; 5,60 \pm 0,0316 g para codornices pertenecientes a T2, T1, To y T3 (Tabla 3). Los resultados se encuentran dentro de los rangos de la estirpe, más no de aquellos encontrados por Melo et al. (2008) donde alcanzó una media de 6,88 g usando $0,25 \%$ de harina de algas marinas.

\section{Evaluación económica}

La mayor rentabilidad se obtuvo con el tratamiento T2 con $20 \%$ de proteína más la adición de $0,19 \%$ de aminoácidos sintéticos, con índices de beneficio/ costo de 1,30 usD lo que significa que por cada dólar gastado durante el periodo de investigación en la producción de codornices de postura, se obtuvo un beneficio neto de 0,30 USD. (Tabla 4 ). 


\section{Tabla 4}

Evaluación económica en la producción de codornices tratadas con aminoácidos sintéticos con bajos niveles de proteína bruta en la dieta

\begin{tabular}{|c|c|c|c|c|}
\hline \multirow{2}{*}{ CONCEPTO } & \multicolumn{4}{|c|}{ TRATAMIENTOS } \\
\hline & TO & $\mathrm{T} 1$ & T2 & T3 \\
\hline \multicolumn{5}{|l|}{ EGRESOS } \\
\hline Costo de Codornices 1 & 212,50 & 212,50 & 212,50 & 212,50 \\
\hline Concentrado 2 & 212,12 & 187,34 & 189,31 & 185,73 \\
\hline Sanidad 3 & 6,58 & 6,58 & 6,58 & 6,58 \\
\hline Prevención 4 & 2,11 & 2,11 & 2,11 & 2,11 \\
\hline Bioseguridad 5 & 8,38 & 8,38 & 8,38 & 8,38 \\
\hline Construcciones e instalaciones 6 & 14,67 & 14,67 & 14,67 & 14,67 \\
\hline Servicios básicos 7 & 5,00 & 5,00 & 5,00 & 5,00 \\
\hline Mano de Obra 8 & 55,78 & 55,78 & 55,78 & 55,78 \\
\hline Embalaje del producto final 9 & 3,02 & 2,92 & 3,19 & 3,04 \\
\hline TOTAL DE EGRESOS & 520,15 & 495,27 & 497,50 & 493,79 \\
\hline \multicolumn{5}{|l|}{ INGRESOS } \\
\hline Venta de huevos 10 & 502,55 & 485,95 & 530,95 & 507,05 \\
\hline Codornaza 11 & 16,00 & 16,00 & 16,00 & 16,00 \\
\hline Aves en producción 12 & 97,60 & 98,40 & 99,20 & 97,60 \\
\hline TOTAL DE INGRESOS & 616,15 & 600,35 & 646,15 & 620,65 \\
\hline BENEFICIO/COSTO (USD) & 1,18 & 1,21 & 1,30 & 1,26 \\
\hline \multicolumn{2}{|c|}{$\begin{array}{l}\text { 1. Costo de codornices } \$ 1,70 / \text { codorniz. } \\
\text { 2. } 22 \% \mathrm{~PB} \$ 0,64 / \mathrm{kg} ; 21 \% \mathrm{~PB} \$ 0,62 / \mathrm{Kg} ; 20 \% \mathrm{~PB} \$ 0,61 / \\
\mathrm{kg} ; 19 \% \mathrm{~PB} \$ 0,60 / \mathrm{Kg} \text {. } \\
\text { 3. Costo de antibióticos } \$ 3,08 / \text { Trat y Vitaminas } \$ \\
\text { 3, } 50 / \text { Trat. } \\
\text { 4. Costo de Vacuna } \$ 0,01 / \text { dosis y Yodo } \$ 0,63 / \mathrm{ml} \text {. } \\
\text { 5. Costo Desinfectantes } \$ 8,38 \text {. } \\
\text { 6. Depreciación de instalaciones y equipos } \$ 14,66 \text {. }\end{array}$} & \multicolumn{3}{|c|}{$\begin{array}{l}\text { 7. Costo de luz y agua } \$ 20 \text {. } \\
\text { 8. Costo de mano de obra } \$ 1,89 / \text { jornal. } \\
\text { 9. Costo de caja } \$ 0,15 / \text { unidad. } \\
\text { 10. Venta de Huevos } \$ 0,05 / \text { unidad. } \\
\text { 11. Venta del Abono } \$ 2 / \text { saco. } \\
\text { 12. Cotización aves en producción } \$ 0,80 / \text { ave. }\end{array}$} \\
\hline
\end{tabular}

Fuente: Elaboración propia

\section{CONCLUSIONES}

La crianza de codornices reporta muchos beneficios favorables, debido a la baja inversión inicial, fácil adaptación al medio, además de obtener alta producción de huevos que permiten al coturnicultor desarrollar un negocio altamente rentable y de rápida recuperación de la inversión.

El incremento de la demanda en el mercado ecuatoriano por el consumo de huevos de codorniz, permitió que los avicultores ampliar las granjas con la producción de esta especie innovando sus instalaciones, realizando investigaciones y probando nuevas dietas que permiten alcanzar altos niveles productivos. 
Elaborar dietas para codornices considerando el 20\% de proteína bruta más 0,19\% de aminoácidos sintéticos, ya que de acuerdo a los resultados obtenidos se esperan obtener mejores parámetros productivos y económicos, mediante la utilización de este nivel.

Dado al consumo de aminoácidos como metabolitos libres suministrados en la dieta, es preciso continuar estudios de valoración metabólica de aminoácidos en el producto final para esta especie animal. 


\section{REFERENCIAS}

Amarrilla, P., \& Albornoz, M. (2013). Guía para el coturnicultor. Todo lo necesario para la incubación de codorniz y para el avicultor. 1ed. Buenos Aires: Dunken. p 85.

Begin J, \& Insko W. (1994). The effects of dietary protein level on the reproductive performance of coturnix breeder hens. p. 142-143.

Castañón, M. (1994). Estudio recapitulativo de la nutrición nitrogenada en las aves. sn. st. México. DF, Edit. Limusa-Grupo Noriega. p 565.

Ciriaco, P., \& Roncal, H. (2016). Efecto del uso de aditivos en dietas de codornices reproductores (Coturnix japonica) bajo condiciones de verano en la costa central. Anales científicos 77(1), 118-123.

Hurtado, N., Torres, D., \& Ocampo, Á. (2013). Efecto de los niveles de proteína sobre el desempeño de codornices japonesas en fase de postura. Orinoquia, 17(1), 30-37.

Iqbal, M., Roohi, N., Akram, M., \& Khan, O. (2015). Egg quality and egg geometry influenced by mannan-oligosaccharides (MOs), a prebiotic supplementation in four close bred flocks of Japanese quail breeders (Coturnix coturnix japonica). Pakistan J Zool 47: 641-648.

Labier, M., \& Leclercq, B. (1992). Nutrition et alimentation des volailles. 20.

Melo, T., Ferreira, V., Oliveira, J., Carneiro, A., Moura, A., Silva, C., \& Nery, V. (2008). Calidad del huevo de codornices utilizando harina de algas marinas y fosfato monoamónico. Revisado en: http://www.uco.es/organiza/ servicios/publica/az/php/img/web/22_10_17_05CalidadMelo.pdf.

Moura, A., Soares, R., Fonseca, J., Vieira, R., \& Nery, V. (2009). Efecto de diferentes niveles dietéticos de lisina total sobre la calidad del huevo de codornices japonesas (Coturnix japonica). Revisado en: http://www. bioline.org.br/pdf?lao9010.

Obregón, R. (2012). Utilización de diferentes niveles de promotor de crecimiento natural hibotek en la cría, desarrollo y levante de codornices y su efecto hasta alcanzar el pico de producción. Repositorio digital. еsPосн. Ecuador. pp. 66-69.

Oliveira, A., Furlan, A., Murakami, A., Moreira, I., Scapinello, C., \& e Martins, E. (1999). Exigência nutricional de lisina para codornas japonesas (Coturnix coturnix japonica) em postura. Rev. Bras. Zootecn., 28: 1050-1053

Ortega, N. (2011). Determinación del efecto de diferentes temperaturas microambientales en las fases inicial, crecimiento, desarrollo y postura en codornices. Repositorio digital. ESPOCH. Ecuador. pp. 78,77.

Orellana, J. (2014). Información sobre el sector avícola del Ecuador. XXXII Seminario Internacional Mercado Avícola. Quevedo, Ecuador.

Özsoy, A., \& Aktan, S. (2011). Estimation of genetic parameters for body weight and egg weight traits in Japanese quails. Trends Anim Vet Sci J 2: 17-20. 
Panda, B., \& Singh, R. (1990). Development in processing quail meat and eggs. Worlds Poult Sci J 46: 219- 234.

Portillo, J. (2005). Evaluación de la interacción genotipo-nivel de proteína en codorniz japonesa reproductora (Coturnix coturnix japonica) en trópico seco. Repositorio Digital. Universidad de Colima. México. p. 89.

Pitakpongjaroen, T., \& Wiboonpongse, A. (2015). Optimal production systems in highland communities in Chiang Mai Province. Italian Oral Surgery. Vol. 5, pp. 22-29.

Ruiz, B. (2016). Repuntan pollo y huevo en la avicultura latinoamericana. Industria avícola 63: 10-38.

Salinas, M. (2015). Acondicionamiento de equipos existentes en la producción de codornices en la finca villa margarita maria. International Journal of Soil Science, 10(1), 1-14. https://doi.org/10.3923/ijss.2017.32.38

Shrivastav, A., \& Panda, B. (1999). A review of quail nutrition research in India. World's Poultry Science Journal, 55:1, 73-81.

Syakalima, M., Simuunza, M., \& Zulu V. (2017). Chicken diseases and their ethno-botanical treatments among the rural poor in southern Zambia, Africa en Livestock Research for Rural Development. Vol. 29, núm. 1.

Tapia, X. (2010). Evaluación económica de diferentes niveles de proteína bruta utilizados en la alimentación para codornices en producción. Repositorio Digital. Universidad Nacional de Loja. Ecuador. p. 63-64.

Tovar, J., Narváez, L., \& Agudelo, L. (2015). Tipificación de la gallina criolla en los agroecosistemas campesinos de producción en la zona de influencia de la selva de Florencia (Caldas). Luna Azul. 41(41), 57-72.

Yamane, T, Ono, K, \& Tanaka, T. (2007). Protein requirement of laying japanese quail. British Poultry Science. 20:4, 379-383, DOI: 10.1080/00071667908416596 